\title{
Lipid peroxidation as a measure of oxygen free radical damage in the very low birthweight infant
}

\author{
T E Inder, P Graham, K Sanderson, B J Taylor
}

\begin{abstract}
Oxygen free radical mediated tissue injury is implicated as a major factor in the pathogenesis of the long term complications seen in the premature infant, and direct evidence of their role in the development of these long term problems is lacking. A prospective observational study of $78 \%$ of very low birthweight infants admitted to a level III neonatal intensive care unit in 1992 was undertaken to determine the relationship between lipid peroxidation products, antioxidant activity, and outcome. Lipid peroxidation (malondialdehyde-thiobarbituric acid, MDA-TBA) and antioxidant activity (vitamin $E$ and glutathione peroxidase activity) were measured in 22 very low birthweight infants in the cord blood and the infant's blood at 24 hours, 48 hours, and 1 week of age and correlated with outcome measures. The normal range for these measures was established in the cord blood samples of 48 consecutive healthy full term infants.
\end{abstract}

The concentration of MDA-TBA at 1 week correlated with the number of days of oxygen treatment and number of days of positive pressure ventilatory support. Controlling for gestational age and antenatal complications simultaneously the MDA-TBA concentration remained significantly associated with the number of days of oxygen treatment and the number of days of positive pressure ventilatory support. Glutathione peroxidase was low in the premature and full term infants consistent with the low concentrations of selenium known to be present in southern New Zealand. There was evidence of a quadratic relationship between vitamin $E$ at 1 week and the total number of days of supplementary oxygen requirement, with both high and low values associated with increased oxygen requirement. This association, however, did not remain after controlling for gestational age and antenatal complications. These results support the role of oxygen free radicals in mediating tissue damage associated with the development of chronic lung disease in the premature infant.

(Arch Dis Child 1994; 70: F107-111)

Free oxygen radicals are extremely reactive species that although crucial to a wide range of normal biological processes, are potentially damaging. They can disrupt lipid cell membranes, destroy cell enzyme functions, alter DNA, and lead to cell death. ${ }^{12}$ Free oxygen radicals appear to have a role in mediating tissue injury in hyperoxia, ${ }^{1-4}$ in damage associated with reperfusion after ischaemia, and in inflammatory processes. ${ }^{1256}$ These are all mechanisms implicated in the pathogenesis of the major complications of prematurity including bronchopulmonary dysplasia, retinopathy of prematurity, and intraventricular haemorrhage. ${ }^{7-9}$

Oxygen free radical damage is usually prevented by a series of enzymatic defences such as superoxide dismutase, glutathione peroxidase, and catalase and by a series of non-enzymatic quenching antioxidants such as vitamins $\mathrm{E}, \mathrm{A}$, and glutathione. ${ }^{1}$ The premature infant has poorly developed antioxidant systems and therefore may be at increased risk of radical damage. ${ }^{7}$ 8 10-12 This risk may be even greater for infants in New Zealand where environmentally low selenium concentrations may result in low activities of the selenium dependent enzyme glutathione peroxidase. ${ }^{13} 14$

A major limitation in this area of research has been the absence of an accurate and reliable measure of free radical activity. Oxygen free radicals react with lipids to produce lipid peroxide products. ${ }^{2}$ Measurement of lipid peroxide concentrations by the malondialdehyde-thiobarbituric acid (MDATBA) assay is the most widely recognised measure of free radical activity used in current clinical research. ${ }^{1516}$ Free radical activity in the very low birthweight infant has been assessed by expired ethane and pentane, ${ }^{8}$ but there are no reports of attempts to measure lipid peroxidation products and antioxidant activity in the sera of premature infants and correlate these concentrations with outcome.

\section{Patients and methods}

Serum concentrations of MDA-TBA and vitamin $\mathrm{E}$ and glutathione peroxidase activity were measured in samples of (i) cord blood and (ii) infant's blood at 24 hours, 48 hours, and 1 week of age in 22 very low birthweight infants admitted to the neonatal intensive care at Dunedin Public Hospital. All infants less than $1500 \mathrm{~g}$ and/or less than 32 weeks' gestation were eligible to participate. Of all very low birthweight infants born during the study period October 1991-November 1992, $78 \%$ were enrolled. For comparison, cord blood samples from 48 full term infants were analysed.

Full details of the pregnancy, birth history, and neonatal course including details of nutrition, blood transfusions, oxygen supple- 
mentation, and ventilatory support were collected prospectively. Ultrasound scans of the head were performed in the first 48 hours, at 1 week, and 6 weeks of age. Screening for retinopathy of prematurity was undertaken at 6 weeks of age by a paediatric ophthalmologist. Follow up of neurodevelopmental outcome continues to be collected. All infants in the study were treated in accordance with standard protocols in the neonatal unit. Oxygenation was monitored by continuous pulse oximetry (Nelcor N100 and N200, target oxygen saturation $87-95 \%$ ) and by frequent blood gas analysis. Arterial oxygen tension was maintained at $6 \cdot 0-10 \cdot 0 \mathrm{kPa}$. All infants were receiving parentally administered glucose and six $(27 \%)$ infants also received enteral feeding from the second day onward. Total parenteral nutrition (TPN) was commenced on the third day in $17(78 \%)$ infants using $1 \mathrm{~g} / \mathrm{kg} /$ day Trophamine (Kendall McGaw Laboratories, USA) with $10-15 \%$ dextrose. Intralipid (Kabi Pharmacia) was commenced in 14 (64\%) infants on day $3-4$ at $1 \mathrm{~g} / \mathrm{kg} / \mathrm{day}$. The amino acid mixture and the lipid were both increased as tolerated by $0.5 \mathrm{~g} / \mathrm{kg} /$ day to a maximum of 3 $\mathrm{g} / \mathrm{kg} /$ day. Supplementary trace elements of zinc, copper, manganese, iodine, chromium, molybdenum, and selenium at $1.4,0.6,0.04$, $0.05,0.005,0.002$, and $0.04 \mu \mathrm{mol} / \mathrm{kg} /$ day were routinely added to the TPN solution. Supplementary vitamins were added to the TPN solution as MVI Paediatric (RhônePoulenc Rorer) $1.1 \mathrm{ml} / \mathrm{kg} /$ day giving 506 USP units/kg/day vitamin A, 88 USP units/kg/day vitamin $\mathrm{D}$, and 1.54 USP units/kg/day vitamin $\mathrm{E}$.

\section{SAMPLE ANALYSIS}

MDA-TBA was measured in plasma after lipid extraction by reverse phase high performance liquid chromatography (HPLC) using a Shimadzu RF-530 HPLC fluorescence detector (excitation $515 \mathrm{~nm}$, emission $553 \mathrm{~nm}$ ) coupled to a Shimadzu Chromatopac C-R3A integration. Intra-assay and interassay variability were 3 and $5 \%$ respectively. ${ }^{17} 18$

Vitamin E was measured by HPLC method of Bieri $^{19}$ with intra-assay coefficient of variation less than $2 \%$.

Glutathione peroxidase was measured with t-butyl hydroperoxide as a substrate by a modification of the method by Paglia and Valentine. ${ }^{20}$ Each run was standardised against a stored haemolysate with intra-assay and interassay variability of $2 \%$ and $<10 \%$ respectively.

Results are reported as mean (SD) unless specifically described otherwise.

\section{CHARACTERISTICS OF THE STUDY GROUP}

MDA-TBA, glutathione peroxidase, and vitamin $E$ were measured in the cord sera of 48 consecutive healthy full term infants with mean birth weight 3320 (420) g (range 2480-4860 g) with mean gestation $39 \cdot 4(0 \cdot 8)$ weeks (range 37-43 weeks). MDA-TBA, glutathione peroxidase, and vitamin $\mathrm{E}$ were analysed in serum samples of 22 very low birthweight infants from cord blood and the infant's blood at 48 hours and 1 week. Fifteen of these infants also had sera analysed at 24 hours of age. Of the 22 very low birthweight infants, 13 were boys and nine girls. The mean gestation was $27 \cdot 9(2 \cdot 2)$ weeks (range $24-32$ weeks). The mean birth weight was 1080 (253) (range 580-1480 g).

The presence of chronic lung disease was defined as supplementary oxygen requirement for greater than 28 days with an abnormal chest radiograph and respiratory status.

ETHICS

The study protocol was approved by the ethics committee of Otago Area Health Board and written consent was obtained from the parents to allow participation of their infants.

\section{STATISTICAL ANALYSIS}

Conventional analysis of variance was used for between group comparison of normally distributed variables while the Kruskal-Wallis non-parametric test was used for variables which were clearly not normally distributed. Fisher's exact test was used for between group comparisons of dichotomous variables. The cord and postnatal concentrations of MDATBA and vitamin $\mathrm{E}$ and glutathione peroxidase activities and their ratio were analysed in relation to days of ventilator and oxygen dependence by linear regression. For ease of interpretation regression coefficients were converted to correlation coefficients. The influence of gestational age, sex, and antenatal variables on these correlations were analysed via a multivariate linear regression model.

\section{Results}

Very low birthweight infants who developed chronic lung disease were of earlier gestation $(F=3.93, \mathrm{p}=0.07)$ and lower birth weight $(F=7.09, \mathrm{p}=0.02)$, with greater maximum oxygen requirement in the first 12 hours $(F=6.83, \mathrm{p}=0.03)$. Antenatal factors did not differ significantly between the outcome groups (table 1).

Table 1 Characteristics of infants with chronic lung disease and with normal respiratory outcome

\begin{tabular}{lcc}
\hline & $\begin{array}{l}\text { Chronic } \\
\text { lung } \\
\text { disease } \\
(n=16)\end{array}$ & $\begin{array}{l}\text { Normal } \\
\text { respiratory } \\
\text { outcome } \\
(n=6)\end{array}$ \\
\hline Gestational age (weeks) & $27 \cdot 3(2 \cdot 2)$ & $29 \cdot 3(1 \cdot 8)$ \\
Birth weight (g) & $1000(230)$ & $1290(190)$ \\
Sex (male:female) & $10: 6$ & $4: 2$ \\
Antepartum haemorrhage & $2 / 16$ & $3 / 6$ \\
Prolonged rupture of membranes & $7 / 16$ & $5 / 6$ \\
Pre-eclampsia & $4 / 16$ & $0 / 6$ \\
Elective delivery & $11 / 16$ & $6 / 6$ \\
Maximum fractional inspired & & \\
Oxygen in first 12 hours (\%) & $47 \cdot 5(18)$ & $23 \cdot 5(3)$ \\
Death & $0 / 16$ & $0 / 6$ \\
Days ventilated & $18 \cdot 3(12 \cdot 6)$ & $1 \cdot 7(2 \cdot 3)$ \\
Days in oxygen & $65 \cdot 8(32 \cdot 9)$ & $4 \cdot 8(2 \cdot 9)$ \\
Oxygen at term & $8 / 16$ & $0 / 6$ \\
Retinopathy & $0 / 16$ & $0 / 6$ \\
Intraventricular haemorrhage & $1 / 16$ & $0 / 6$ \\
$\quad$ Grade 1-2 & $1 / 16$ & $0 / 6$ \\
Grade 3-4 & & \\
\hline
\end{tabular}


Table 2 Mean (SD) MDA-TBA, vitamin E, and glutathione peroxidase in the cord blood of full term and premature infants who subsequently did or did not develop chronic lung disease

\begin{tabular}{llll}
\hline & & \multicolumn{2}{l}{ Premature infants } \\
\cline { 3 - 4 } & $\begin{array}{l}\text { Full term } \\
\text { infants } \\
(n=48)\end{array}$ & $\begin{array}{l}\text { Chronic lung } \\
\text { disease absent } \\
(n=6)\end{array}$ & $\begin{array}{l}\text { Chronic lung } \\
\text { disease present } \\
(n=16)\end{array}$ \\
\hline MDA-TBA $(\mu \mathrm{mol} / 1)$ & $63 \cdot 0(9 \cdot 4)$ & $71 \cdot 6(9 \cdot 2)$ & $85 \cdot 3(17 \cdot 5)$ \\
Vitamin E $(\mu \mathrm{mol} / /)^{\star}$ & $11 \cdot 2(3 \cdot 0)$ & $8 \cdot 4(2 \cdot 3)$ & $6 \cdot 1(2 \cdot 8)$ \\
Glutathione peroxidase $(\mathrm{U} / 1)$ & $89(19)$ & $74(21)$ & $56(17)$ \\
\hline
\end{tabular}

*Vitamin $\mathrm{E}$ conversion factor: $\mu \mathrm{mol} / \mathrm{l}=\mathrm{mg} / 1 \times 2 \cdot 32$.
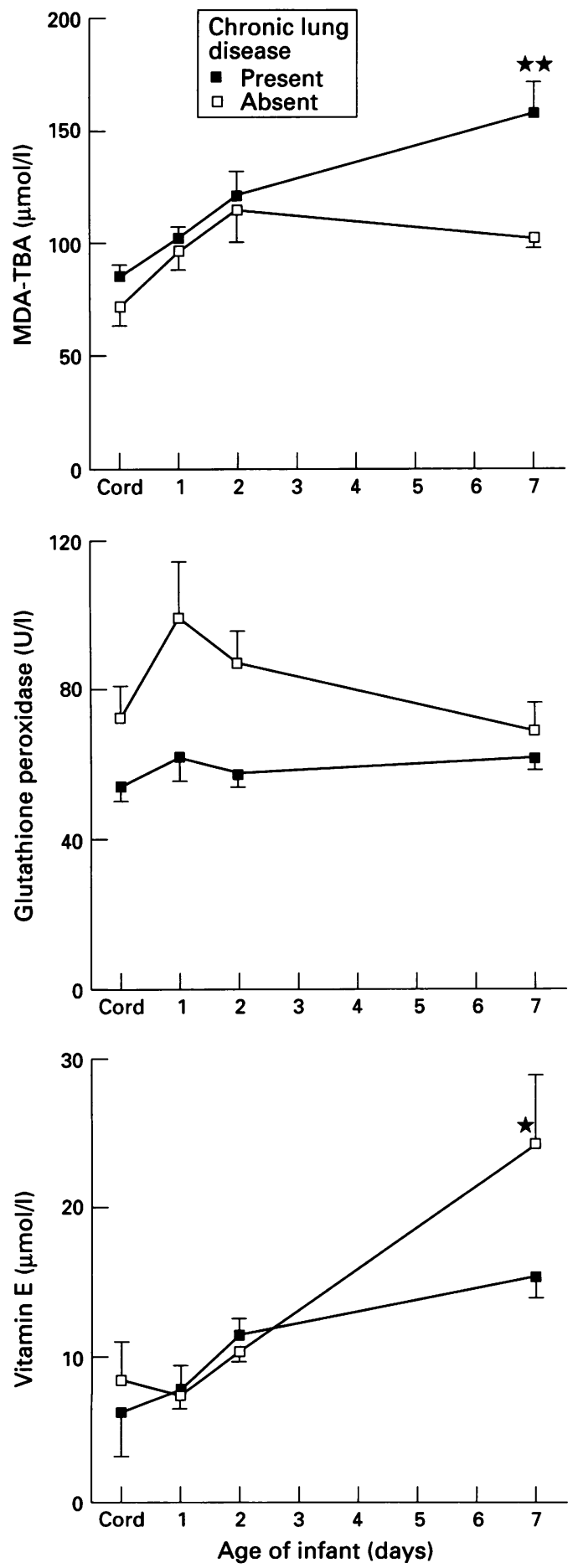

Variations in plasma values of $M D A-T B A$, glutathione peroxidase, and vitamin $E$ in premature infants with and without chronic lung disease; values are mean (SE); ${ }^{\star} p<0 \cdot 1,{ }^{\star}{ }^{*} p<0.05$. Vitamin $E$ conversion factor: $\mu m o l l=m g / \times 2 \cdot 32$.
In the cord blood samples of the premature infants who developed chronic lung disease the concentration of MDA-TBA was higher (Kruskal-Wallis test, $\chi^{2}=27 \cdot 5, p=0 \cdot 0001$ ), the concentration of vitamin $\mathrm{E}$ lower (KruskalWallis test, $\chi^{2}=17 \cdot 95, p=0 \cdot 0001$ ), and glutathione peroxidase activity lower $\left(\chi^{2}=11 \cdot 5\right.$, $\mathrm{p}=0.003$ ) than the healthy full term infants (table 2). These values were not influenced by maternal age, previous obstetric history, complications during the pregnancy, mode of delivery, antenatal steroid use, duration of labour, or Apgar scores at 1 or 5 minutes.

The concentrations of MDA-TBA and vitamin $\mathrm{E}$ and glutathione peroxidase activity at each sample time postnatally did not correlate with the simultaneous measurements of ventilation status, oxygen requirement, form of nutrition, or transfusion volume.

For infants who developed chronic lung disease the mean MDA-TBA concentrations were higher with the mean vitamin $E$ and glutathione peroxidase values lower than those infants without chronic lung disease (figure).

Preliminary analysis suggested that the cord, day 1 , and day 2 measurements were not related to the total number of days of oxygen treatment.

Regression analysis of the concentration of MDA-TBA at 1 week showed a strong correlation with the total number of days positive pressure ventilatory support $(r=0.54$, $\mathrm{p}=0.009$ ) and the total number of days of oxygen treatment $(r=0.61, \mathrm{p}=0.003)$. There was evidence of a quadratic relationship between vitamin $\mathrm{E}$ at 1 week and the total number of days supplementary oxygen treatment, with both low and high concentrations associated with increased oxygen requirement. (For the quadratic model $R^{2}=0.34, \mathrm{p}=0.04$, while for the linear model $R^{2}=0 \cdot 02, \mathrm{p}=0.53$. A comparison of the two models based on the reduction in error sum of squares yielded $F=7 \cdot 7, \mathrm{p}=0 \cdot 017$.) Vitamin $\mathrm{E}$ at 1 week also showed evidence of a quadratic relationship with days of positive pressure ventilatory support, although the strength of the relationship was not as strong as that found in relation to the number of days of supplementary oxygen. $\quad\left(R^{2}=0.27, \mathrm{p}=0.09\right.$ for quadratic model; $R^{2}=0.015, \mathrm{p}=0.63$ for linear model. Fit of quadratic significantly better $F=5 \cdot 207$, $p=0.037$.) The activity of glutathione peroxidase activity at 1 week was weakly inversely related to the total days of positive pressure ventilatory support $(r=-0.398, p=0.08)$ but did not correlate with the total number of days of supplementary oxygen treatment $(r=-0.05$, $\mathrm{p}=0 \cdot 83$ ).

The association between outcome measures and MDA-TBA, vitamin $\mathrm{E}$, and glutathione peroxidase was investigated further by controlling for the potentially confounding factors via multiple linear regression. The confounders controlled were gestational age, and the presence or absence of antepartum haemorrhage, prolonged rupture of membranes, and pre-eclampsia. Controlling simultaneously for these factors slightly strengthened the positive association between 
MDA-TBA and the number of days of supplementary oxygen requirement (partial $r=0.66$, $t=3.57, \mathrm{p}=0.0026)$ and between MDA-TBA and the number of days of positive pressure ventilation (partial $r=0.58, \quad t=2.85$, $\mathrm{p}=0.0115$ ). After controlling for the potentially confounding factors glutathione peroxidase was not associated with either total oxygen requirement (partial $r=0.26, t=1.036$, $\mathrm{p}=0.318$ ) or with the number of days of positive pressure ventilation (partial $r=0 \cdot 12$, $t=-0.477, \mathrm{p}=0.641)$. Vitamin $\mathrm{E}$ did not remain significantly associated with oxygen requirement $(F=1.33, \mathrm{p}=0.30)$ or days of positive pressure ventilatory support $(F=1 \cdot 102, \mathrm{p}=0 \cdot 366)$ after controlling for these possible confounders.

\section{Discussion}

Our results demonstrate a correlation of the concentrations of MDA-TBA with respiratory outcome in the very low birthweight infant. The small numbers in our study limit the conclusions relating to glutathione peroxidase and vitamin E. MDA-TBA is the most extensively used measure of lipid peroxidation in current clinical research. ${ }^{151621}$ Individual research laboratories have refined their own assays making comparisons between values, methods, and investigations difficult. ${ }^{15-1721}$ The assay has been criticised as a measure of radical activity and resultant lipid peroxidation as it is indirect and can be contaminated by other thiobarbituric acid reactive species. These sources of error have been reduced in our assay by the addition of butylated hydroxytoluene to limit intra-assay production of MDA-TBA and the use of lipid extraction and ion exchange high pressure chromotography to remove interfering chromogens. ${ }^{17} 18$

MDA-TBA is not a sensitive measure of radical activity requiring high levels of radical activity to alter its concentration. ${ }^{21}$ The finding of significant increases in MDA-TBA indicates that the infants who developed chronic lung disease were exposed to very high levels of radical activity. The increase in cord concentrations of MDA-TBA in the premature infants who later developed chronic lung disease may be an explanation of the well known vulnerability of premature infants to maternal factors. Mild increases in lipid peroxidation (MDA-TBA) have been found before delivery in all women, but with women with complicated pregnancies (pre-eclampsia) significantly higher concentrations of lipid peroxides and significantly reduced antioxidant activity have been reported. ${ }^{22} 23$ Our results support the hypothesis that maternal factors before delivery increase the vulnerability of the premature infant to long term complications by increased free radical activity and a reduction in antioxidant protection.

The antioxidant status of the premature infant has been shown to be poorly developed. ${ }^{7}$ 10-12 Antioxidant enzymes mature throughout gestation. Low antioxidant enzyme activity in the premature infants' lungs poorly equip them for assisted ventilation in a hyper- oxic environment. ${ }^{4}$ Antenatal administration of glucocorticoids matures the antioxidant enzyme system, ${ }^{24}$ whereas antenatal thyrotrophin releasing hormone impairs antioxidant enzyme maturation. ${ }^{25} 26$ Surfactant replacement treatment has produced only limited improvement in the rates of chronic lung disease. $^{2728}$ The role of the antioxidant enzyme system in the onset and progression of hyperoxic lung injury in premature experimental animals suggest that the premature infant may benefit from therapeutic intervention with antioxidant enzyme preparations. ${ }^{1029-31}$ Rosenfeld et al evaluated the effect of subcutaneous superoxide dismutase in a randomised blinded controlled study of 45 infants with severe respiratory distress syndrome (ventilator dependent with fractional inspired oxygen $>0.7$ at 24 hours) administered until infants were in room air without ventilator support. ${ }^{32}$ Radiological and clinical signs of bronchopulmonary dysplasia were significantly reduced in surviving infants who received superoxide dismutase (3/14 treated $v 11 / 17$ non-treated). There was no difference in the number of days of oxygen dependence in the two groups. The therapeutic use of antioxidant enzyme preparations requires further research.

Vitamin $\mathrm{E}$ has multiple antioxidant functions that allow the quenching of free radicals, particularly the superoxide radical. ${ }^{33}$ The superoxide radical is an important destroyer of polyunsaturated fatty acid components of biological membranes. Newborn infants usually receive high doses of vitamin $\mathrm{E}$ in colostrum producing the marked increase (3-4 fold) in vitamin $\mathrm{E}$ concentrations in the first week of life. ${ }^{3435}$ Our results suggest that the infants who developed chronic lung disease did not experience the anticipated rise in vitamin $E$ concentrations during their first week of life. This was not explained by differences in feeding patterns. Premature infants may require higher doses of vitamin $\mathrm{E}$ to maintain adequate serum concentrations. ${ }^{36}$ Our results suggested that infants in our study with both low, that is $<11.7 \mu \mathrm{mol} / \mathrm{l}(<5 \mathrm{mg} / \mathrm{l})$ and high, that is $>28$ $\mu \mathrm{mol} / \mathrm{l}(>12 \mathrm{mg} / \mathrm{l})$ vitamin $\mathrm{E}$ concentrations at 1 week were at high risk for development of chronic lung disease. These infants received very similar intakes of vitamin $E$ in their first week and it is hypothesised that the infants with raised plasma concentrations may be mobilising vitamin $\mathrm{E}$ from their tissues, increasing oxidant vulnerability at the tissue level.

Glutathione peroxidase requires selenium as an essential component. New Zealand, particularly in the southern region, is selenium deficient and low glutathione peroxidase activity has been shown in adults and infants in this region. ${ }^{1314}$ Very low birthweight infants in this study had some of the lowest glutathione peroxidase activities reported. Glutathione peroxidase is a protective antioxidant enzyme and the reduced activity in these infants will increase their vulnerability to radical damage. ${ }^{29} 30$ The inability to show any significant difference between activities of 
glutathione peroxidase in relation to respiratory outcome in our study may be due to the fact that the values are uniformly extremely low. New Zealand has a high incidence of bronchopulmonary dysplasia, not explained purely by a high survival rate, in premature infants. ${ }^{31}$ Selenium deficiency with resulting low glutathione peroxidase activity may be a factor increasing vulnerability for New Zealand infants to radical mediated tissue injury.

This investigation shows that in very low birthweight infants the probability of chronic lung disease increases with documented free radical activity evidenced by increased lipid peroxidation products. The role of the antioxidants vitamin $\mathrm{E}$ and glutathione peroxidase in the vulnerability of these infants requires further investigation. Demonstration of the causative role of free radicals requires intervention studies with the possibility of using lipid peroxidation as a measure of the effectiveness of the antioxidant intervention. MDATBA appears to be a useful measure in exploring the role of free radicals in the diseases of the premature infant.

The authors would like to thank Vicki Phillips, Glenys Taylor for their dedicated work with the MDA-TBA assays in these infants. We would also like to acknowledge the financial infants. We would also like to acknowledge the financial the New Zealand Lottery Board. Mr Graham was funded by the Health Research Council of New Zealand.

1 Freeman BA, Crapo JD. Biology of disease. Free radicals and tissue injury. Lab Invest 1982; 47: 412-26.

2 Sies H. Oxidative stress: from basic research to clinical application. Am f Med 1991; 91 (suppl 3C): 31-9.

3 Phelps DL Neonatal oxygen toxicity - is it preventable? Pediatr Clin North Am 1982; 29: 1233-40.

4 Wispe JR, Roberts RJ. Molecular basis of pulmonary oxygen toxicity. Clin Perinatol 1987; 14: 651-66.

5 Kloner RA, Przyklenk K, Whittaker P. Deleterious effects of oxygen radicals in ischaemia-reperfusion. Circulation 1989; 80: 1115-27.

$6 \mathrm{McCord}$ JM. Oxygen-derived free radicals in postischemic tissue injury. $N$ Engl f Med 1985; 312: 159-63.

7 Frank L. Antioxidants, nutrition and bronchopulmonary dysplasia. Clin Perinatol 1992; 19: 541-61.

8 Pitkkanen OM, Hallman M, Anderson SM. Correlation of free radical-induced lipid peroxidation with outcome in very low birthweight infants. $\mathcal{F}$ Pediatr 1990; 116: 760-4.

9 Muller DPR. Vitamin E therapy in retinopathy of prematurity. Eye 1992; 6: 221-5.

10 Frank L, Sosenko IRS. Development of lung antioxidant enzyme system in late gestation: possible implications fo the prematurely born infant. $\mathcal{F}$ Pediatr $1987 ; 110$ : 106-10

11 Lindman JHN, van Zoergen-Grobben D, Schrijver J. The total free radical trapping ability of cord blood plasma in preterm and term babies. Pediatr Res 1989; 26: 20-4.

12 Sullivan JL, Newton RB. Serum antioxidant activity in neonates. Arch Dis Child 1988; 63: 748-57.

13 Dolamore BA, Brown J, Darlow BA, George PM, Sluis KB, Winterbourn CC. Selenium status of Christchurch infants and the effect of diet. $N Z M$ Med $\Im$ 1992; 105: 139-42.

14 Sluis KB, Darlow BA, George PM, Mogridge N, Dolamore B, Winterbourn CC. Selenium and glutathione
Dow, peroxidase levels in a low selenium community. Pediatr Res 1992; 32: 189-94.

15 Ohwaka H, Ohishi N, Yagi K. Assay for lipid peroxides in animal tissues by thiobarbituric acid reaction. Anal Biochem 1979; 95: 351-8.

16 Draper $\mathrm{HH}$, Hadley $\mathrm{M}$. Malondialdehyde determination as index of lipid peroxidation. Methods Enzymol 1990; 186: 421-31.

17 Wade CR, van $\mathrm{Rij}$ AM. Plasma thiobarbituric acid reactivity: reaction conditions and the role of iron, antioxidants and lipid peroxy radicals on the quantitation of oxidants and lipid peroxy radicals on the quantita

18 Wade CR, Jackson PG, van Rij AM. Quantification of malondialdehyde (MDA) in plasma, by ion-pairing reverse phase high performance chromatography. Biochemical Medicine 1985; 33: 291-6.

19 Bieri J. Simultaneous determination of alpha-tocopherol and retinol in plasma or red cells by high pressure liquid chromatography. Am f Clin Nutr 1979; 32: 2143-9.

20 Paglia DE, Valentine WN. Studies on the quantitative and qualitative characterisation of erythrocyte glutathione peroxidase. F Lab Clin Med 1967; 70: 158-69.

21 Pogastsa G, Schaper W. Is malondialdehyde a marker of the effect of oxygen free radicals in rat heart tissue? Basic Res Cardiol 1991; 86: 266-72.

22 Davidge ST, Hubel CA, Brayden RD, Capeless EC, McLaughlin MK. Sera antioxidant activity in uncomplicated and pre-eclamptic pregnancies. Obstet and Gynecol 1992; 79: 897-901.

23 Wilson DC, Tubman R, Bell N, Halliday HL, McMaster D. Plasma manganese, selenium and glutathione peroxidase levels in the mother and newborn infant. Early Hum Dev 1991; 26: 223-6.

24 Frank L, Lewis PL, Sosenko IRS. Dexamethasone stimulation of fetal rat lung antioxidant enzyme activity in parallel with surfactant stimulation. Pediatrics 1985; 75: 569-74.

25 Rodriguez-Pierce M, Sosenko IRS, Frank L. Prenatal thyroid releasing hormone and thyroid releasing hormone plus dexamethasone lessen the survival of newborn rats during prolonged high $\mathrm{O}_{2}$ exposure. Pediatr Res 1992; 32: 407-11.

26 Chen Y, Whitney PL, Frank L. Negative regulation of antioxidant enzyme gene expression in the developing fetal rat lung by prenatal hormonal treatments. Pediatr Res 1993; 33: 171-6.

27 The OSIRIS collaborative group. Early versus delayed neonatal administration of synthetic surfactants - the judgment of OSIRIS. Lancet 1992; 340: 1363-9.

28 Jobe AH. Pulmonary surfactant therapy. $N$ Engl $7 \mathrm{Med}$ 1993; 328, 861-9.

29 Lockitch G, Jacobsen B, Quigley G. Selenium deficiency in low birthweight infants. An unrecognised problem. F Pediatr 1989; 114: 865-70.

30 Huston RK, Jelen BJ, Vidgoff J. Selenium supplementation in low birthweight premature infants; relationship to trace metals and antioxidant enzymes. Fournal of Parenteral and Enteral Nutrition 1991; 15: 556-9.

31 Darlow BA, Horwood LJ. Regional variations in chronic lung disease in very low birthweight infants: a prospective population based study 7 Paediatr Child Health 1992; 28 301-5.

32 Rosenfeld W, Evans H, Concepcion L, Jhaveri R, Schaeffer $\mathrm{H}$, Friedman A. Prevention of bronchopulmonary dysplasia by administration of bovine superoxide dismutase in preterm infants with resp
syndrome. $\mathcal{A}$ Pediatr 1984; 105: 781-5.

33 Engle WA, Yoder MC, Baurley JL. Vitamin E decreases superoxide anion production by polymorphonuclear leucocytes. Pediatr Res 1988; 23: 245-8.

34 Armode-Spalding K, D'Harlingue AE, Phillips BL, et al. Tocopherol levels in infants $<1000$ grams receiving MVIPaediatric. Pediatrics 1992; 88: 992-4.

35 Phillips BL, Franck LS, Greene H. Vitamin E levels in premature infants during and after intravenous multivitamin supplementation. Pediatrics 1987; 80: 680-3.

36 Kelly FJ, Rodger W, Handel J, Smith S, Hall MA. Time course of vitamin $\mathrm{E}$ repletion in the premature infant. $\mathrm{BrF}$ Nutr 1990; 63: 631-8. 